\title{
O REGIME INTERNACIONAL DE PROTEÇ̃̃O À PROPRIEDADE INTELECTUAL E A QUESTÃO DOS PAÍSES EM DESENVOLVIMENTO
}

\author{
Luiz Gonzaga Silva Adolfo ${ }^{1}$ \\ Ana Bárbara Moreira Tesche ${ }^{2}$
}

\section{RESUMO}

A Propriedade Intelectual é um fator de destaque na política mundial, sendo relevante para a compreensão do desenvolvimento tecnológico e científico dos países. A questão do desenvolvimento pode ser vinculada diretamente à evolução do regime internacional da Propriedade Intelectual. Por meio da análise desta evolução e da "Agenda do Desenvolvimento" estabelecida pelos países em desenvolvimento, busca-se compreender a relevância destas questões nas relações internacionais contemporâneas.

Palavras-chave: Agenda para o Desenvolvimento da OMPI. Países em desenvolvimento. Propriedade Intelectual.

\section{INTRODUÇÃO}

Os chamados Direitos Intelectuais, aqueles que englobam a criatividade e o desenvolvimento humano, nasceram tardiamente. Porém, diferentemente dos outros direitos, acabaram nascendo internacionais ou, de certo modo, supranacionais.

$\mathrm{Na}$ reflexão sobre os problemas contemporâneos de Propriedade Intelectual, não se pode deixar de englobar questões tão relevantes quanto as que permeiam os países em desenvolvimento. A partir do contexto da historicidade deste regime foi possível levantar e enumerar as questões pertinentes a eles.

Propõe-se neste artigo descrever a historicidade do regime de Propriedade Intelectual, elencando suas particularidades, e, a partir da "Agenda do Desenvolvimento", destacar algumas dificuldades desses países em relação às possíveis dificuldades quanto à flexibilização dos problemas.

O problema a analisar, mesmo que os países em desenvolvimento tenham se engajado na flexibilização de questões relevantes ao desenvolvimento no que permeia a Propriedade Intelectual, eles continuam a realizar acordos com países desenvolvidos que visam aumentar a proteção do atual regime.

Como hipótese, embora seja grande a luta, especialmente do Brasil, para manter a flexibilidade do regime e aumentar o grau de discussão das questões dentro da OMPI, e não mais tão amplamente dentro do TRIPS, os países em desenvolvimento acabam por liderar tais discussões. 
Para a realização deste estudo utilizou-se como fontes de pesquisa bibliografia sobre o tema, documentos de fontes primárias e secundárias, tendo destaque as Convenções de Paris para a Proteção da Propriedade Industrial e de Berna para a Proteção das Obras Literárias e Artísticas, além de livros e diversos artigos.

Tem-se como objetivo caracterizar e compreender a historicidade da Propriedade Intelectual e como a extrema regularização pode constituir um obstáculo ao avanço tecnológico dos países em desenvolvimento. Também se pretende mostrar a lógica do capital e o valor econômico da propriedade intelectual. Questiona-se, então, se de algum modo a Propriedade Intelectual pode vir a se tornar um obstáculo ao desenvolvimento.

\section{A CONSTRUÇÃO DO REGIME INTERNACIONAL DA PROPRIEDADE INTELECTUAL}

É a partir do século XIX que a literatura especializada na área aponta como o início do despertar dos Direitos de Propriedade Intelectual nos mais diversos países. Os Estados nacionais passaram, então, a cooperar em matéria de Propriedade Intelectual. Tais relações se deram primeiramente na área bilateral, onde os países evocavam o princípio da reciprocidade. O Reino Unido, país que na época liderava a produção econômica mundial, sendo o maior produtor de manufaturas e tecnologias industriais, pode ser considerado um bom exemplo, uma vez que estabeleceu Atos de proteção à propriedade industrial de outros países em seu território, desde que estes garantissem a propriedade industrial em seu próprio território. Os países em que se negociavam acordos bilaterais eram, em sua maioria, países europeus.

A Propriedade Intelectual veio ganhar legitimidade no final do século XIX, quando se justificou sua proteção como direitos naturais humanos e surgiu a primeira forma de normatização do regime internacional. Para Jaguaribe e Brandelli: ${ }^{3}$

Com a Revolução Industrial surge um reconhecimento crescente da relevância das inovações e as patentes passam a ter cada vez maior relevância. Todos esses sistemas de proteção tinham habitualmente o mesmo alcance da soberania dos príncipes que os outorgavam. Com o aumento do comércio dos produtos industrializados, surge 0 interesse em buscar ampliar a área de proteção desses privilégios. Esse interesse conduziu, após o sobressalto provocado pela resistência liberal à expansão do sistema patentário, na segunda metade do século XIX, às primeiras propostas de criação de um sistema extranacional. As convenções de Paris e de Berna surgem nesse contexto, a partir de 1880. A gestão das convenções gera uma demanda de uma burocracia fixa e surge o Secretariado das Convenções. 
A Convenção de Paris para proteção da Propriedade Industrial, de 20 de março de 1883, foi a primeira tentativa em relação a uma maior uniformização das leis nacionais. Ela permitiu um razoável grau de flexibilidade às legislações nacionais, desde que fossem respeitados alguns princípios fundamentais nela elencados, como o tratamento nacional (art. 2), estabelecendo que os nacionais de cada um dos países membros possam, em todos os outros países membros, ter a mesma proteção, vantagens e direitos concedidos pela legislação do país a seus nacionais, sem que nenhuma condição de domicílio ou de estabelecimento seja exigida, e o princípio de prioridade unionista (art. 4), onde o primeiro pedido de patente ou desenho industrial depositado em um dos países membros serve de base para os próximos depósitos, efetuados pelo mesmo depositante, ou seja, um direito de prioridade. O terceiro princípio básico é o de interdependência dos direitos. Segundo o artigo 4 bis, "as patentes requeridas nos diferentes países da União por nacionais de países da União serão independentes das patentes obtidas para a mesma invenção nos outros países, membros ou não da União". E o quarto, o princípio da territorialidade, estabelece que a proteção conferida pelo Estado através da patente ou do registro do desenho industrial tem validade somente nos limites territoriais do país que a concede.

Já a Convenção de Berna, de 9 de setembro de 1886, trata da proteção da Produção Literária e Artística, ou seja, o Direito do Autor e seus direitos conexos, elencando alguns princípios, como 0 de tratamento nacional. Segundo Basso, "a Convenção deu origem a uma entidade internacional que assumiria a tarefa de harmonizar os direitos dos Estados-Partes."

Basso $^{5}$ também destaca a criação de secretarias especializadas para fazerem a gestão e o controle das convenções. Assim, "a partir das Convenções, foram criadas duas "Uniões", de Paris e de Berna, e dois órgãos centrais encarregados de aplicá-las: Bureau (Secretaria) Internacional da União Industrial, em 1884, e Bureau (Secretaria) Internacional da União Literária, em 1888". Mais tarde, estas duas secretarias foram unificadas na chamada BIRPI (Bureaux Internationaux Reunis pour la protection de la Propriété Intellectuelle).

A partir destes marcos do século XIX constituiu-se e legitimou-se a Propriedade Intelectual como um regime, uma vez que $\mathrm{Krasner}^{6}$ os define:

Regimes can be defined as sets of implicit or explicit principles, norms, rules, and decision-making procedures around which actors' expectations converge in a given area of international relations. Principles are beliefs of fact, causation, and rectitude. Norms are standards of behavior defined in terms of rights and obligations. Rules are specific prescriptions or proscriptions for action. Decision-making procedures are prevailing practices for making implementing collective choice. $^{7}$

Após a criação das duas Convenções internacionais, o regime apenas produziu alguns acordos que revisaram as Convenções anteriores. No caso da Propriedade Industrial, as revisões são as de Bruxelas (1900), Washington 
(1911), Haia (1925), Londres (1934), Lisboa (1958) e Estocolmo (1967). Na Convenção sobre Direitos Autorais as modificações foram realizadas em Berlim (1908), Roma (1928), (1948), Estocolmo (1967) e em Paris (1971).

Como se vê, o regime sofreu poucas modificações desde 1893. As alterações em tal regime começaram a ser feitas com a mudança significativa que ocorreu no sistema internacional a partir do fim das duas Guerras Mundiais.

Com a finalidade de se responder às necessidades do Pós-Guerra, no dia 14 de julho de 1967 a "Convenção de Estocolmo" criou a então Organização Mundial da Propriedade Intelectual - OMPI (World Intellectual Property Organization - WIPO), que possui desde 1974 o status de Organismo Especializado da ONU. Com a criação da OMPI, as Convenções realizadas até aquele momento passaram a ser de sua responsabilidade, e o Bureaux Internationaux Reunis pour la protection de la Propriété Intellectuelle - BIRPI deixou de existir. Segundo Basso, ${ }^{8}$ "com toda a experiência obtida desde o fim do século passado, a OMPI pode melhor desempenhar suas funções de legislar sobre os direitos de propriedade intelectual para países com desenvolvimento e sistemas de direito diversos, de tradição romano-germânica, common law, orientação socialista e outros".

O papel central que a OMPI veio a desempenhar é o de por em vigor novos tratados sobre a matéria, sendo responsável, a partir de seu órgão de Conferência (CO) por prestar assistência técnico-jurídica aos países, em desenvolvimento ou não, que buscam as questões de Propriedade Intelectual. Para Basso,${ }^{9}$ tal Organização passou por certo grau de adaptação:

\begin{abstract}
Frente às constantes necessidades de adaptação, a OMPI submete os tratados a constantes estudos e, quando necessário, a conferências de revisão. Coopera com os países em desenvolvimento para a melhor proteção da propriedade intelectual. No que concerne ao registro internacional de marcas, desenhos e modelos industriais, a OMPI tem procurado as mais variadas formas de cooperação entre seus países-membros.
\end{abstract}

Na década de 1980 o regime passou por sua mudança mais drástica. Com a eleição de Ronald Reagan (1981-1989), os Estados Unidos tornaram-se mais inflexíveis na matéria de Propriedade Intelectual e submeteram o tema na agenda do GATT (General Agreement on Tariffs and Trade). Na Rodada Uruguai passou-se não apenas a discutir os temas de liberalização do comércio, como também os temas de propriedade intelectual.

O fato é que os Estados Unidos já possuíam regras claras de vinculação da Propriedade Intelectual com o comércio. Basso ${ }^{10}$ escreve a este respeito:

Ainda na fase pré-TRIPS, o unilateralismo ou bilateralismo americano se consolidou graças à "Section 301". Em termos gerais, a "Section 301 (a)" do "Trade Act", de 1974, autoriza o United State Trade 
Representative - USTR a promover ações quando um ato, política ou prática de um país estrangeiro afeta os direitos dos Estados Unidos estabelecidos em algum tratado comercial, ou injustificadamente sobrecarrega ou restringe o comércio dos Estados Unidos.

Não há dúvida de que o unilateralismo do "Special 301" levou, como acontece ainda hoje, muitos países a concordar com acordos internacionais e aceitar compromissos não cobiçados com vistas a evitar as possíveis sanções americanas. Além do mais, grande parte da ajuda americana a países em desenvolvimento já vinha atrelada à proteção da propriedade intelectual.

Em síntese, o unilateralismo/bilateralismo americano serviu para elevar o nível de proteção dos direitos de propriedade intelectual nos ordenamentos internos dos países em desenvolvimento.

Com as negociações da Rodada Uruguai e as ameaças norte-americanas de utilização das sanções da "Section 301", as negociações foram conduzidas para a aprovação do texto do Agreement on Trade Related Aspects of Intellectual Property Rights - TRIPS (Acordo Relativo aos Aspectos do Direito da Propriedade Intelectual Relacionados com o Comércio - ADPIC), se fixando com a conclusão da Rodada Uruguai e a criação da Organização Mundial do Comércio - OMC.

A partir do TRIPS pode-se almejar uma consolidação do regime de propriedade intelectual, onde as normas passam a ser mais rígidas e inflexíveis, aumentando sua abrangência. Estabeleceram-se procedimentos para conferir eficácia às normas, uma vez que o TRIPS difere dos outros acordos, pois, ao fazer parte da OMC, enquadra os países signatários no mecanismo de resolução de disputas desta Organização, tornando-se um poderoso mecanismo de execução.

Ao analisar o Regime Internacional de Propriedade Intelectual se vê como se tornou complexo devido a seu aprofundamento e evolução, englobando a mais ampla diversidade de acordos bilaterais, multilaterais, organizações internacionais, convenções regionais e internacionais.

Diante da análise do regime e de sua historicidade, faz-se necessária a compreensão da relação entre 0 atual regime $e$ as questões de desenvolvimento que lhe estão vinculadas, proposta apresentada no ponto a seguir.

\section{REGIME INTERNACIONAL DA PROPRIEDADE INTELECTUAL E AS QUESTÕES DE DESENVOLVIMENTO}

As questões de Propriedade Intelectual vinculadas ao desenvolvimento refletem a globalização do mundo em que se vive. Além de, obviamente, afetarem os países em desenvolvimento, em geral na América Latina e na África, elas também se vinculam diretamente aos países desenvolvidos. 
Como já mencionado, o "Special 301", criado pelos Estados Unidos, levou as mais diferentes questões ao debate e a sua vinculação no plano internacional. Isto fica confirmado no texto de Basso ${ }^{11}$ quando afirma: "Em 2000, o USTR tornou público um relatório sobre a 'Special 301', no qual divulgou que mais de setenta países têm revisado suas leis de propriedade intelectual com vistas a evitar as sanções comerciais da ' 301 '.

Dentre as inúmeras questões e respostas que existem, pretende-se apenas elucidar e destacar algumas de maior relevância.

Em primeiro lugar, a posição de fragilidade enfrentada por todos os países em desenvolvimento frente às questões de proteção da propriedade intelectual, uma vez que não possuem as condições dos países desenvolvidos, não contam com 0 alto grau de P\&D destes e nem condições de implementação e controle de leis com alto grau de proteção.

Para Basso: ${ }^{12}$

Certamente os países em desenvolvimento estão em desvantagem na medida em que níveis maiores de proteção dos direitos de propriedade intelectual asseguram maiores vantagens comparativas para os países desenvolvidos. Contudo, mesmo assim os países em desenvolvimento participam de negociações bilaterais e de acordos de investimento na mesma forma em que faziam antes do TRIPS, porque acreditam que tal prática é indispensável para a promoção do desenvolvimento econômico, mesmo frente à inexistência de qualquer evidência de que a adoção de tais acordos e, por conseguinte, de padrões mais elevados de propriedade intelectual, tenham efeitos positivos nos processos internos de disseminação tecnológica e inovação.

O segundo ponto é o destaque que alguns países em desenvolvimento adquiriram no plano internacional como defensores de uma diminuição de regulação internacional. É o caso do Brasil, da Argentina e da Índia, dentre outros. O Brasil ganha especial destaque, pois, com a intensificação dos debates, acabou por desenvolver uma grande potencialidade discursiva defendendo não o fim de tal acordo, mas as flexibilidades previstas no TRIPS. Para Basso: ${ }^{13}$

A melhor alternativa para os países em desenvolvimento e em menor desenvolvimento relativo é explorar com habilidade as flexibilidades inerentes ao TRIPS e, com base nos padrões já existentes de propriedade intelectual, promover seus próprios sistemas de inovação, suas necessidades de investimento, assim como buscar novas formas de proteção desses direitos que possam estimular a inovação e o desenvolvimento tecnológico local com baixos custos sociais.

O terceiro ponto é a tentativa dos países desenvolvidos, com destaque especial para os Estados Unidos, de tentar extinguir as flexibilidades e o caráter singular de que dispõem os países em desenvolvimento dentro do TRIPS e da própria OMC. Os países em desenvolvimento tentam eliminar tais 
flexibilidades com a questão dos TRIPS-plus, que são esquemas bilaterais e regionais para atingir resultados que implicam maiores compromissos destes países com a Propriedade Intelectual, através de acordos bilaterais de Propriedade Intelectual e acordos de livre-comércio, como afirma Basso: ${ }^{14}$

\begin{abstract}
Em síntese, os acordos de investimento (BITs) e de comércio (FTAs), na era pós-TRIPS, constituem instrumentos potenciais por meio dos quais se podem impor novas obrigações de propriedade intelectual, aos países em desenvolvimento. O "novo bilateralismo", portanto, em vez de utilizar a OMC ou a OMPI para novas negociações, estimula e impõe uma agenda expansionista, por meio de múltiplos tratados, bilaterais e regionais, capazes de assegurar um sistema global de propriedade intelectual mais rígido do que aquele resultante do TRIPS.
\end{abstract}

Com a breve exposição destas questões de destaque e debate na agenda internacional, é possível ter um maior entendimento de sua relevância no que tange ao regime de proteção, a seu processo de andamento e às estratégias que podem e lhe são vinculadas, em especial para o desenvolvimento de determinados países. A partir das estratégias ganha notável destaque a "Agenda para o Desenvolvimento", exposta dentro da OMPI.

\title{
3 O BRASIL E A “AGENDA PARA O DESENVOLVIMENTO” DA OMPI
}

A "Agenda para o Desenvolvimento" teve seu início a partir de um grande movimento dentro da Organização das Nações Unidas (ONU) em busca de um desenvolvimento mais igualitário entre os diferentes países signatários. Portanto, não constitui um movimento único dentro da organização.

$\mathrm{Na} 40^{\mathrm{a}}$ Rodada de Reuniões das Assembleias dos Estados Membros da OMPI (40 Series of Meeting of the Assemblies of the Member States of WIPO), realizada em Genebra entre 27 de setembro e 5 de outubro de 2004, deu-se 0 início da perspectiva desenvolvimentista que acabou por reavivar a Organização Mundial da Propriedade Intelectual, em um esforço conjunto do Brasil, da Argentina e dos demais países em desenvolvimento, ${ }^{15}$ recebendo também apoio da Índia, mesmo que este país não tivesse patrocinado tal projeto.

Para Brandelli, ${ }^{16}$ a "Agenda para o Desenvolvimento" segue certa tendência dentro das Organizações Internacionais:

Como se percebe, a proposta de uma "Agenda para o Desenvolvimento na OMPI", apresentada em 2004 durante a Assembleia-Geral daquela Organização, não é um fato isolado. Ao contrário, segue tendência verificada em diversos foros nacionais e internacionais, tanto em países em desenvolvimento como em países desenvolvidos. 
A proposta obteve repercussão significativa no âmbito internacional, proporcionando um crescimento objetivo do Brasil como ator de maior relevância no sistema internacional, como aponta Souza: ${ }^{17}$

\begin{abstract}
Inicialmente, ela significa o início efetivo do primeiro governo Lula (2003-2006) refletido na OMPI. Em segundo lugar, a Agenda retoma as grandes discussões e embates que polarizaram a OMPI ao longo dos anos. Ao questionar a concentração tecnológica nas mãos dos países desenvolvidos, evidencia nessa organização internacional sua preocupação com a distribuição de poder tecnológico. Além do que, exibe o temor por níveis de harmonização mais profundos do que TRIPS que funcionariam de maneira deletéria aos países em desenvolvimento, cerceando ainda mais os direitos a que podiam legitimamente exercer no sistema internacional de patentes.
\end{abstract}

Além do interesse brasileiro, os demais países em desenvolvimento têm tentado desenvolver um contraponto aos então conhecidos TRIPS-plus, buscando manter as flexibilidades que existem em tal acordo, protegendo os países em grau de desenvolvimento industrial e tecnológico inferior de terem que adotar as mesmas normas internacionais de países em grau de desenvolvimento muito diferenciado.

Para Souza: ${ }^{18}$

É nesse ínterim que se originou um embate técnico-político no SCP e
na OMPI como um todo, impulsionado por dois diferentes
posicionamentos. De um lado, os países desenvolvidos e algumas
economias em transição. De outro, a maior parte dos países em
desenvolvimento, incluindo o Brasil que propõe, dentre outros, uma
discussão condicionada a suficiência do relatório descritivo das
patentes para que essas sejam melhor replicadas uma vez terminado
o prazo das patentes, e a inclusão de uma cláusula relativa a
repartição equitativa de benefícios quando constatado que dada
patente se utilizou de conhecimentos tradicionais e recursos
genéticos, previsão essa que toma como base os dispositivos da
Convenção sobre a Diversidade Biológica -CDB, de 1992.

A partir de então, no chamado Provisional Committee on Proposals Related to a WIPO Development Agenda (CPDA), que propõe 111 ações, divididas em áreas temáticas e com a intenção de ajudar estes países a não ceder e ampliar as flexibilidades, existem:

O propósito da "Agenda para o Desenvolvimento" é discutir na OMPI as preocupações apontadas anteriormente quanto aos efeitos da propriedade intelectual sobre o desenvolvimento. Busca, igualmente, equilibrar a pauta de trabalhos da Organização, que após o Acordo TRIPS, vinha se dedicando principalmente à discussão de propostas de ampliação dos DPI, particularmente nas agendas digital e de patentes. Não havendo evidências de que o fortalecimento dos DPI contribua por si só, automática e necessariamente, para 0 desenvolvimento tecnológico, econômico, social, parece legítimo e lógico que uma das principais organizações internacionais que se ocupa da matéria, a OMPI, também passasse a levar em conta a 
dimensão do desenvolvimento nos seus trabalhos, até porque se trata de um órgão vinculado às Nações Unidas. ${ }^{19}$

Tal proposta não é definitiva; buscam-se sempre novos resultados e maior engajamento, tanto dos países que englobam a agenda como da comunidade internacional:

Após a apresentação da "Agenda", na Assembleia-Geral de 2004, as discussões prosseguiram em 2005 no âmbito das chamadas Reuniões Intersessionais da própria Assembléia-Geral da OMPI. Em 2005 foi constituído um Comitê Provisório para trabalhar na redação de propostas concretas, ao longo de 2006, de onde resultou um conjunto de mais de 100 propostas apresentadas por diversos membros da Organização, não apenas os "Amigos do Desenvolvimento", mas também por países como Bareine, Chile, Colômbia, EUA, Grupo Africano, México, Reino Unido etc. ${ }^{20}$

O ilustrado acima demonstra maior engajamento internacional e maior consciência advinda dos países em desenvolvimento quanto ao seu papel na sociedade internacional e à valorização de sua importância enquanto atores internacionais.

\section{CONSIDERAÇÕES FINAIS}

A questão do regime internacional de Propriedade Intelectual e as questões relacionadas ao desenvolvimento dos países, tanto desenvolvidos como em desenvolvimento, como foi aqui desenvolvido, é de relevância internacional.

Pode-se analisar que a relação entre a importância do comércio e a importância do desenvolvimento de países em situação precária acaba por entrar em colisão. Em uma porção considerável das vezes vem prevalecendo o interesse dos países desenvolvidos, fato que deve permanecer como uma luta constante dos países em desenvolvimento, para que possam atingir seus objetivos de política para propriedade intelectual "que sejam condizentes com metas mais amplas de promoção do desenvolvimento dos países pobres. Os países em desenvolvimento não devem ser obrigados a aceitar padrões de proteção dos direitos de propriedade intelectual impostos pelos países em desenvolvimento para, em troca, obterem acesso a mercados e investimentos" 21 .

Com o aumento da pressão exercida pelos países em desenvolvimento, em especial dentro da "Agenda para o Desenvolvimento" da OMPI, vem aumentando a conscientização e a implementação de normas diferenciadas para estes países e a manutenção destas diferenças nas já existentes: "Talvez seja o mais significativo, na condução de prioridades e desafios, ter presente que comércio e investimento não são fins em si mesmos, mas meios para se atingir o desenvolvimento equilibrado e sustentável" ${ }^{22}$. 
As discussões aqui ressaltadas moldam a atual situação do regime de Propriedade Intelectual no cenário internacional e os debates inseridos dentro da Organização Mundial de Propriedade Intelectual.

\section{THE SYSTEM OF INTERNATIONAL PROTECTION OF INTELLECTUAL PROPERTY AND THE QUESTION OF DEVELOPING COUNTRIES}

\section{ABSTRACT}

Intellectual Property is a major factor in world politics, being relevant for the understanding of the countries scientific and technological development. The question of development can be directly linked to the evolution of the international regime of intellectual property. Through the analysis of this evolution and the "Development Agenda" established by developing countries, we try to understand the relevance of these issues in contemporary international relations.

Key-words: WIPO Development Agenda. Intellectual Property.Developing countries.

\section{NOTAS}

1. Advogado, Mestre e Doutor em Direito pela Universidade do Vale do Rio dos Sinos UNISINOS; professor dos Cursos de Direito da Universidade Luterana do Brasil - ULBRA (Gravataí/RS); do Instituto Brasileiro de Gestão de Negócios - IBGEN (Porto Alegre/RS); e da Escola Superior de Administração, Direito e Economia (Porto Alegre/RS). Membro da Associação Brasileira de Direito Autoral - ABDA - com sede em São Paulo/SP; da Associação Portuguesa de Direito Intelectual - APDI - com sede em Lisboa; e da Comissão Especial de Propriedade Intelectual da Ordem dos Advogados do Brasil, Secção Rio Grande do Sul. Endereço eletrônico: gonzagaadolfo@yahoo.com.br

2. Graduada em Relações Internacionais pelo Centro Universitário La Salle UNILASALLE. Voluntária de Iniciação Científica. Endereço eletrônico: ana_barbara_tesche@hotmail.com.

3. JAGUARIBE, Roberto; BRANDELLI, Otávio. Propriedade Intelectual: espaços para os países em desenvol-vimento. In: VILLARES, Fábio [Org.]. Propriedade Intelectual: tensões entre o capital e a sociedade. São Paulo: Paz e Terra, 2007. p. 270-305. p. 276.

4. BASSO, Maristela. O Direito Internacional da Propriedade Intelectual. Porto Alegre: Livraria do Advogado, 2000, p. 90.

5. BASSO, Maristela. O Direito Internacional..., op. cit., p. 38.

6. KRASNER, Stephen D. [Ed.]. International Regimes. Ithaca and London: Cornell University Press, 1983, p. 2.

7. Os regimes podem ser definidos como implícitos ou explícitos, conjuntos de princípios, normas, regras e procedimentos de tomada de decisão em torno dos quais as expectativas dos atores convergem em uma dada área das relações internacionais. Princípios são crenças sobre fatos, causação ou retidão. Normas são padrões de comportamento definidos em termos de direitos e obrigações. Regras são prescrições específicas ou proibições para ação. Procedimentos de decisão são práticas predominantes para se fazerem e implementarem escolhas coletivas (tradução livre dos autores). 
8. BASSO, Maristela. O Direito Internacional..., op. cit., p. 142.

9. BASSO, Maristela. O Direito Internacional..., op. cit., p. 146.

10. Idem. Propriedade Intelectual na era pós-OMC. Porto Alegre: Livraria do Advogado, 2005, p. 18.

11. BASSO, Maristela. Propriedade Intelectual..., op. cit., p. 21.

12. BASSO, Maristela. Propriedade Intelectual..., op. cit., p. 22.

13. Ibidem, p. 106.

14. Idem, p. 22.

15. "Bolívia, Cuba, Egito, Equador, Irã, Peru, Quênia, República Dominicana, Serra Leoa, Tanzânia, Venezuela e Uruguai - o chamado grupo "Amigos do desenvolvimento." BRANDELLI, Otávio. Agenda para o Desenvolvimento em matéria de Propriedade Intelectual. Artigo apresentado no seminário nacional da Propriedade Intelectual. Brasília, 2006, p. 9. Disponível em: <http://www2.mre.gov.br/dipi/2006-08-Brandelli.pdf>. Acesso em: 28 jul. 2011.

16. Ibid., p. 8.

17. SOUZA, Fernando Cassibi de. O sistema internacional de propriedade intelectual no alvorecer do século XXI: a preponderância da OMC e a retomada da OMPI na agenda de discussões em matéria normativa de patentes. In: Encontro Regional da ANPUH/Rio: Memória e Patrimônio, 14. Rio de Janeiro, UniRio, 19 a 23 de julho de 2010, p. 7. Disponível em: $\quad<$ http://www.encontro2010.rj.anpuh.org/resources/anais/8/1278003432 ARQUIVO_ANPUH_2010.Final.pdf>. Acesso em: 28 jul. 2011.

18. SOUZA, Fernando Cassibi de. O sistema internacional.., op. cit., p. 6.

19. BRANDELLI, Otávio. Agenda para..., op. cit. p. 10.

20. BRANDELLI, Otávio. Agenda para..., op. cit., p. 10.

21. BASSO, Maristela. Propriedade Intelectual..., op. cit., p. 76.

22. Ibid., p. 109.

\section{REFERÊNCIAS}

ALMEIDA, Paulo. Roberto de. A Propriedade Intelectual na política exterior e nos processos de integração econômica. Revista Brasileira de Política Internacional, n. 2, p. 80-92, jul.-dez. 1993.

AMARAL JÚNIOR, Alberto do [Coord.]. Direito do Comércio Internacional. São Paulo: Juarez de Oliveira, 2002.

BARBOSA, Denis Borges. Uma introdução à Propriedade Intelectual. 2. ed. Rio de Janeiro: Lumen Juris, 2003.

. Da noção de bens imateriais. Propriedade Intelectual. 2002. Disponível em: <http://www.denisbarbosa.addr.com/136.doc>. Acesso em: 20 ago. 2010.

BARRAL, Welber; PIMENTEL, Luiz Otávio (Orgs.). Propriedade Intelectual e Desenvolvimento. Florianópolis: Fundação Boiteux, 2007.

; CORREA, Carlos M. [Orgs.]. Direito, Desenvolvimento e Sistema Multilateral de Comércio. Florianópolis: Fundação Boiteux, 2008. 
BASSO, Maristela. O Direito Internacional da Propriedade Intelectual. Porto Alegre: Livraria do Advogado, 2000.

. Propriedade Intelectual na era pós-OMC. Porto Alegre: Livraria do Advogado, 2005.

BRANDELLI, Otávio. Agenda para o Desenvolvimento em matéria de Propriedade Intelectual. In: SEMINÁRIO NACIONAL DA PROPRIEDADE INTELECTUAL. Brasília, 2006, p. 8. Anais... (artigo). Disponível em: <http://www2.mre.gov.br/dipi/2006-08-Brandelli.pdf>. Acesso em: 28 jul. 2011.

; GURGEL, Renato Pinheiro do Amaral; MORAES, Henrique Choer. Uma análise do regime internacional da proteção da Propriedade Intelectual à luz dos efeitos sobre políticas públicas de gestão do conhecimento. [s.d.]. Disponível em: <http://www2.mre.gov.br/dipi /SERPRO\%20-\%20artigo\%20\%20Rev1-Final.pdf>. Acesso em: 24 set. 2010.

BRASIL. Ministério de Ciência e Tecnologia. Propriedade Intelectual. [s.d.]. Disponível em: <http://www.mct.gov.br/index.php/content/view/8039.html?tma=5\&tlt=Proprieda de\%20Intelectual>. Acesso em: 20 ago. 2010.

CONVENÇÃO DA UNIÃO DE PARIS PARA A PROTEÇÃO DA PROPRIEDADE INDUSTRIAL, revisão de Estocolmo, 1967. Disponível em: $<$ http://www6.inpi.gov.br/legislacao/outros/convencao_paris.htm>. Acesso em: 13 jul. 2011.

CONVENÇÃO de Berna para Proteção das Obras Literárias e Artísticas, revisão de Paris, 1971 Disponível em: $<$ http://www.fd.uc.pt/.../convencao_berna_obras_literarias-PT.htm>. Acesso em: 13 jul. 2011.

CORREA, Carlos M. Analisando tensões entre patentes e o interesse público: ruma a uma agenda para países em desenvolvimento. In: VILLARES, Fábio (Org.). Propriedade Intelectual: tensões entre o capital e a sociedade. São Paulo: Paz e Terra, 2007. p. 306-333.

CRUZ, Carlos Henrique de Brito. O Redesenho dos Direitos Intelectuais no Comércio Mundial. Revista da ABPI, n. 45, set. 2003. In: SEMINÁRIO NACIONAL DA PROPRIEDADE INTELECTUAL, 23. Anais..., p. 3-6.

CRUZ, Liliam Ane Cavalhieri da. O regime global da propriedade intelectual e a questão do desenvolvimento: o poder dos países em desenvolvimento no campo multilateral. 2008. 140 f. Dissertação (Mestrado em Relações Internacionais) - Programa de Pós-Graduação em Relações Internacionais, Universidade Estadual de Campinas, 2008. Disponível em: 
<http://www.dominiopublico.gov.br/pesquisa/DetalheObraForm.do?select_actio $\mathrm{n}=\& \mathrm{co} \_$obra=114232>. Acesso em: 10 ago. 2010.

DUPAS, Gilberto. Propriedade Intelectual: tensões entre a lógica do capital e os interesses sociais. In: VILLARES, Fábio [Org.]. Propriedade Intelectual: tensões entre o capital e a sociedade. São Paulo: Paz e Terra, 2007. p. 15-25.

FONSECA JR., Gelson; CASTRO, Sérgio Henrique Nabuco de (Orgs.). Temas de Política Externa Brasileira II. 2. ed. São Paulo: Paz e Terra / Brasília: Fundação Alexandre de Gusmão, 1997. 2 volumes.

GONTIJO, Cícero. As transformações do sistema de patentes, da convenção de Paris ao Acordo TRIPS: a posição brasileira. Brasília, maio 2005. Disponível em: $\quad$ <ttp://fdcl-berlin.de/fileadmin/fdcl/Publikationen/C_cero-FDCL.pdf>. Acesso em: 6 out. 2010.

GUSMÃO, Jose Roberto d'Affonseca. Natureza jurídica do direito de propriedade intelectual. [s.d.]. Disponível em: <http://www.glpi.com.br/repository/231.pdf>. Acesso em: 6 out. 2010.

JAGUARIBE, Roberto; BRANDELLI, Otávio. Propriedade Intelectual: espaços para os países em desenvolvimento. In: VILLARES, Fábio [Org.]. Propriedade Intelectual: tensões entre o capital e a sociedade. São Paulo: Paz e Terra, 2007. p. 270-305.

KARACHALIOS, Konstantinos. Estratégias para os países em desenvolvimento na arena internacional: alguns aspectos práticos e teóricos. In VILLARES, Fábio [Org.]. Propriedade Intelectual: tensões entre o capital e a sociedade. São Paulo: Paz e Terra, 2007. p.237-269.

KRASNER, Stephen D. [Ed.]. International Regimes. Ithaca and London: Cornell University Press, 1983.

Structural causes and regime consequences: regimes as intervening variables. In: International Regimes. Ithaca and London: Cornell University Press, 1983. p. 185-205.

LOPES, Reinaldo José. Apelo à flexibilização. Revista Pesquisa, [online], n. 81, nov. $2002 . \quad$ Disponivel em: $<$ http://revistapesquisa.fapesp.br/?art=1987\&bd=1\&pg=1\&lg>. Acesso em: 14 jul. 2010.

MOTTA E ALBUQUERQUE, Eduardo da. Propriedade Intelectual e estratégias para o desenvolvimento. In: VILLARES, Fábio [Org.]. Propriedade Intelectual: tensões entre o capital e a sociedade. São Paulo: Paz e Terra, 2007. p. 140175. 
QUIJANO, José Manuel. Inovação e estratégias para o desenvolvimento. In: VILLARES, Fábio [Org.]. Propriedade Intelectual: tensões entre o capital e a sociedade. São Paulo: Paz e Terra, 2007. p. 176-212.

SANTOS, Laymert Garcia dos. Paradoxos da Propriedade Intelectual. In: VILLARES, Fábio [Org.]. Propriedade Intelectual: tensões entre o capital e a sociedade. São Paulo: Paz e Terra, 2007. p. 41-57.

SOUZA, Fernando Cassibi de. O sistema internacional de Propriedade Intelectual no alvorecer do século XXI: a preponderância da OMC e a retomada da OMPI na agenda de discussões em matéria normativa de patentes. In: ENCONTRO REGIONAL DA ANPUH/RIO: Memória e Patrimônio, 14. Rio de Janeiro, UniRio, 19 a 23 de julho de 2010, p. 7. Anais... Disponível em: <http://www.encontro2010.rj.anpuh.org/resources/anais/8

/1278003432_ARQUIVO_ANPUH_2010.Final.pdf>. Acesso em: 28 jul. 2011.

VICENTE, Dário Moura. A tutela internacional da Propriedade Intelectual. Coimbra: Almedina, 2008.

VILLARES, Fábio [Org.]. Propriedade Intelectual: tensões entre o capital e a sociedade. São Paulo: Paz e Terra, 2007.

Recebido para publicação: 11/08/2011

Aceito para publicação: 13/12/2011 